\title{
Effects on staff outcomes from an intervention for management of neuropsychiatric symptoms in residents of young-onset dementia care units
}

\author{
Citation for published version (APA):
}

van Duinen-van den IJssel, J. C. L., Bakker, C., Smalbrugge, M., Zwijsen, S. A., Appelhof, B., Teerenstra, S., Zuidema, S. U., de Vugt, M. E., Verhey, F. R. J., \& Koopmans, R. T. C. M. (2019). Effects on staff outcomes from an intervention for management of neuropsychiatric symptoms in residents of young-onset dementia care units: A cluster randomised controlled trial. International Journal of Nursing Studies, 96, 3543. https://doi.org/10.1016/j.ijnurstu.2019.03.006

Document status and date:

Published: 01/08/2019

DOI:

10.1016/j.ijnurstu.2019.03.006

Document Version:

Publisher's PDF, also known as Version of record

\section{Document license:}

Taverne

Please check the document version of this publication:

- A submitted manuscript is the version of the article upon submission and before peer-review. There can be important differences between the submitted version and the official published version of record.

People interested in the research are advised to contact the author for the final version of the publication, or visit the DOI to the publisher's website.

- The final author version and the galley proof are versions of the publication after peer review.

- The final published version features the final layout of the paper including the volume, issue and page numbers.

Link to publication

\footnotetext{
General rights rights.

- You may freely distribute the URL identifying the publication in the public portal. please follow below link for the End User Agreement:

www.umlib.nl/taverne-license

Take down policy

If you believe that this document breaches copyright please contact us at:

repository@maastrichtuniversity.nl

providing details and we will investigate your claim.
}

Copyright and moral rights for the publications made accessible in the public portal are retained by the authors and/or other copyright owners and it is a condition of accessing publications that users recognise and abide by the legal requirements associated with these

- Users may download and print one copy of any publication from the public portal for the purpose of private study or research.

- You may not further distribute the material or use it for any profit-making activity or commercial gain

If the publication is distributed under the terms of Article 25fa of the Dutch Copyright Act, indicated by the "Taverne" license above, 


\title{
Effects on staff outcomes from an intervention for management of neuropsychiatric symptoms in residents of young-onset dementia care units: A cluster randomised controlled trial
}

\author{
Jeannette C.L. van Duinen-van den IJssel ${ }^{\mathrm{a}, \mathrm{b}, *}$, Christian Bakker $^{\mathrm{a}, \mathrm{b}, \mathrm{c}, *}$, Martin Smalbrugge ${ }^{\mathrm{d}}$, \\ Sandra A. Zwijsen ${ }^{\mathrm{d}}$, Britt Appelhof ${ }^{\mathrm{a}, \mathrm{b}, \mathrm{e}}$, Steven Teerenstra ${ }^{\mathrm{f}}$, Sytse U. Zuidema ${ }^{\mathrm{g}}$, \\ Marjolein E. de Vugt ${ }^{\mathrm{h}}$, Frans R.J. Verhey ${ }^{\mathrm{h}}$, Raymond T.C.M. Koopmans ${ }^{\mathrm{a}, \mathrm{b}, \mathrm{i}}$ \\ a Radboud University Medical Centre, Radboud Institute for Health Sciences, Department of Primary and Community Care, Nijmegen, the Netherlands \\ ${ }^{\mathrm{b}}$ Radboud Alzheimer Centre, Nijmegen, the Netherlands \\ c Florence, Mariahoeve, Centre for Specialized Care in Young-Onset Dementia, Den Haag, the Netherlands \\ d Amsterdam UMC, Department of General Practice E Elderly Care Medicine/Amsterdam Public Health Research Institute, Amsterdam, the Netherlands \\ e Archipel Care Group, Landrijt, Centre for Specialized Care, Eindhoven, the Netherlands \\ ${ }^{\mathrm{f}}$ Section Biostatistics, Department of Health Evidence, Radboud Institute for Health Sciences, Radboud University Medical Centre, Nijmegen, the Netherlands \\ ${ }^{g}$ Department of General Practice and Elderly Care Medicine, University of Groningen, University Medical Centre Groningen, Groningen, the Netherlands \\ ${ }^{\mathrm{h}}$ School for Mental Health and Neuroscience, Alzheimer Centre Limburg, Maastricht University Medical Centre, Maastricht, the Netherlands \\ i De Waalboog, "Joachim en Anna", Centre for Specialized Geriatric Care, Nijmegen, the Netherlands
}

\section{A R T I C L E I N F O}

Keywords:

Burnout

Job satisfaction

Job demands

Nursing home

Nursing staff

Psychosocial intervention

Young-onset dementia

\section{A B S T R A C T}

Background: Neuropsychiatric symptoms are common in nursing home residents with young-onset dementia and burdensome for nursing staff. It is known that neuropsychiatric symptoms are associated with burn-out complaints and low job satisfaction. An intervention aimed at decreasing neuropsychiatric symptoms in nursing home residents with young-onset dementia might also result in less burnout complaints and job demands and improve job satisfaction in nursing staff.

Objectives: The aim was to evaluate the effect of the intervention on nursing staff burnout, job satisfaction and job demands.

Design: Cluster randomised controlled trial using a stepped wedge design with a total duration of 18 months, with four assessments.

Setting: Thirteen young-onset dementia special care units across the Netherlands were, by means of random allocation software, assigned to three groups crossing over at different time points.

Participants: All nursing staff, in total 391, were invited to participate. 305 nursing staff participated during the course of the study of whom 71 participated in all assessments.

Intervention: An educational program followed by a structured multidisciplinary care program aimed at the management of neuropsychiatric symptoms. The care program consists of evaluation of psychotropic drug prescription followed by detection, analysis, treatment and evaluation of treatment of neuropsychiatric symptoms.

Methods: Emotional exhaustion, depersonalisation and personal accomplishment were assessed with the Utrecht Burnout Scale. Job satisfaction and job demands were assessed with subscales of the Leiden Quality of Work Questionnaire.

Results: The baseline burnout risk on emotional exhaustion and personal accomplishment was average, and low on depersonalisation. The mean scores for job satisfaction were above average and for job demands average. Linear mixed models showed that the intervention had no effect on emotional exhaustion (estimated effect $-0.04,95 \%$ confidence interval -1.25 to 1.16 ), depersonalisation (estimated effect $0.24,95 \%$ confidence interval -0.26 to 0.74 ), personal accomplishment (estimated effect -0.82 , $95 \%$ confidence interval -1.86 to 0.22 ) job satisfaction (estimated effect $-0.40,95 \%$ confidence interval -0.98 to 0.17 ) and job demands (estimated effect $-0.04,95 \%$ confidence interval -0.57 to 0.49 ). A significant difference was found between registered nurses and other nursing staff on emotional exhaustion and job satisfaction. Compared to other staff members, registered nurses' emotional

\footnotetext{
* Corresponding authors at: Primary Care Department, Radboud University Medical Centre, Postbox 9101, 6500, HB, Nijmegen (route 117), the Netherlands. E-mail addresses: jeannette.vanduinen-vandenIJssel@radboudumc.nl (J.C.L. van Duinen-van den IJssel), Christian.Bakker@radboudumc.nl (C. Bakker).
} 
exhaustion scores slightly increased while job satisfaction slightly decreased when using the intervention.

Conclusion: The intervention was not effective on three dimensions of burnout, job satisfaction and job demands. Staff scored positive on the outcomes of interest before implementation of the intervention, leaving little opportunity for improvement.

(c) 2019 Elsevier Ltd. All rights reserved.

\section{What is already known about the topic?}

- Neuropsychiatric symptoms are highly prevalent in nursing home residents with young-onset dementia and are burdening for residents as well as nursing staff. Neuropsychiatric symptoms in late-onset dementia are negatively associated with burnout, job satisfaction and job demands of nursing staff.

- An intervention on the management of neuropsychiatric symptoms in nursing home residents with late-onset dementia was successful in increasing job satisfaction in care staff while job demands remained the same.

- Knowledge regarding nursing staff caring for people with youngonset dementia and knowledge on psychosocial interventions for young-onset dementia are scarce.

\section{What this paper adds}

- Nurses working on young-onset dementia special care units had a low to average risk on developing burnout and had high levels of job satisfaction.

- Compared to care as usual no effect was found of the intervention on job characteristics of the nursing staff.

- The structured multidisciplinary working method is relevant for those nursing homes currently lacking such an approach.

\section{Introduction}

Caring for nursing home residents with dementia is a challenging job. Staff shortages and turnover rates are high, and nursing staff often perceive that there is too much work to do (de Jonge et al., 2008; Harrington and Swan, 2003; Lapane and Hughes, 2007; Ministry of Health Welfare and Sport, 2017). This may even be further complicated by the presence of neuropsychiatric symptoms (Hazelhof et al., 2016). In nursing home residents with so-called young-onset dementia the prevalence of neuropsychiatric symptoms is almost 90\% (Mulders et al., 2016). A recent study on distress in nursing staff working with people with young-onset dementia showed that the majority of the staff perceived high levels of distress related to these symptoms, especially regarding night-time behaviour disorders, agitation/aggression and delusions (van Duinen-van den IJssel et al., 2017). This is in line with research on this issue in late-onset dementia, which also shows that the severity of neuropsychiatric symptoms in particular is a strong predictor of staff distress (Zwijsen et al., 2014a, b).

Studies on the effects of neuropsychiatric symptoms in people with young-onset dementia on job related well-being of nursing staff are scarce. However, prior studies on this topic in late-onset dementia have found several negative associations. A study investigating aggressive behaviours of older residents with dementia found that aggression led to increased emotional exhaustion of the nursing staff (Evers et al., 2001), which is a key component of burnout (Maslach and Jackson, 1981). This effect was stronger for psychological (e.g. verbal aggression, verbal claiming behaviour) compared to physical aggressive behaviours (Evers et al., 2001). In young people with dementia, verbally agitated behaviour is shown by $51 \%$ of the nursing home residents and physically aggressive behaviour is shown by two-thirds of the nursing home residents (Mulders et al., 2016), making staff vulnerable for experiencing emotional exhaustion. Furthermore, aggressive behaviours that are perceived as threatening are especially distressing in nursing staff caring for residents with late-onset dementia (Rodney, 2000). Distress related to neuropsychiatric symptoms in late-onset dementia has been found to adversely affect general health of nursing staff, increase the risk for burnout and affect work ability (Schmidt et al., 2012). These factors underline the necessity of adequate support for nursing staff in the management of these symptoms in young-onset dementia.

Recently, an intervention 'Grip on challenging behaviour' was developed for the management of neuropsychiatric symptoms in nursing home residents with late-onset dementia, and was successful in decreasing the prevalence of these symptoms and increasing job satisfaction of nursing staff (Zwijsen et al., 2015; Zwijsen et al., 2014a, b). In the current study the aforementioned care program was adapted and tailored for use in nursing home residents with young-onset dementia (van Duinen-van den IJssel et al., 2018). This intervention consists of a structured multidisciplinary working method accompanied by an educational program. Although the intervention showed no effect on neuropsychiatric symptoms and psychotropic drug use in nursing home residents with young-onset dementia (Appelhof et al., in press) the intervention might still result in less burnout complaints and improved job satisfaction in nursing staff, because they were given the means to adequately care for this group. Earlier studies in lateonset dementia show that improving nursing staff skills and knowledge regarding dementia and neuropsychiatric symptoms has a positive influence on job satisfaction and on the burden related to neuropsychiatric symptoms (Edvardsson et al., 2009; Hazelhof et al., 2016; Vernooij-Dasssen et al., 2009). Furthermore, the collaboration with other nursing staff, physicians and psychologists may increase feelings of social support. It is known that feelings of control and social support are important for nursing staff perceptions of their job-related well-being (Willemse et al., 2012).

The aim of the current study is to evaluate the effect of the intervention on burnout, job satisfaction and job demands of nursing staff.

\section{Methods}

This study is part of the BEYOND (Behaviour and Evolution in Young ONset Dementia) part II study, which is an intervention study. The design of the BEYOND-II study has been described extensively (van Duinen-van den IJssel et al., 2018), but will be summarised below.

\subsection{Study design}

A stepped wedge design (Table 1) was used to evaluate the effect of the intervention. This design allows clusters (in this case, groups of young-onset dementia special care units) to cross-over from the control to the intervention condition over time, assuring that all units receive the intervention at the end (Brown and Lilford, 2006). Cluster 
Table 1

The stepped wedge design of implementing the intervention.

\begin{tabular}{|l|l|l|l}
\hline & Cluster 1 & Cluster 2 & Cluster 3 \\
\hline T0 & 0 & 0 & 0 \\
\hline T1 & 1 & 0 & 0 \\
\hline T2 & 1 & 1 & 0 \\
\hline T3 & 1 & 1 & 1 \\
\hline
\end{tabular}

$0=$ control condition, $1=$ intervention condition.

Note: Reprinted with permission.

randomisation was used because the intervention was implemented at the staff level. The researchers randomly assigned the special care units to one of three groups by means of a computer-based randomiser. Every six months a new group entered the intervention condition. The control condition consisted of care as usual, without the educational program and without the use of the care program. Implementation of the intervention took place from September 2015 until April 2017. Four assessments were performed every six months during a period of 18 months, namely before implementation (T0), during implementation ( $\mathrm{T} 1$ and $\mathrm{T} 2$ ) and at the end of the implementation process (T3).

\subsection{Participants and setting}

Nursing homes with special care units with dedicated services for younger people with dementia were recruited through their affiliation with the Dutch young-onset dementia Knowledge Centre of which the aim is to further develop the care for these people (Carter et al., 2018). In total, 25 nursing homes were approached for participation. Planned reorganisations and participation in other studies in 12 nursing homes were reasons for refusing participation. In one nursing home, two special care units were excluded from participation because the number of residents on the young-onset dementia care unit was too small (less than 12 residents) (Appelhof et al., 2018). There were no other exclusion criteria. As a result, 13 nursing homes with young-onset dementia special care units, located throughout the Netherlands, participated in this study.

On these special care units care is provided by a multidisciplinary team consisting of nursing staff, elderly care physicians and health care psychologists. In the Netherlands, nursing staff members with nursing education, non-certified nursing assistants as well as recreational therapists work on the special care units. There are 5 levels of nursing education which are comparable with nursing assistant (level 1 and 2), certified nursing assistant (level 3 ), and registered nurse (level 4 and 5). In this study, the whole nursing staff employed in the unit was invited to participate, irrespective of their educational level or hours of employment. Nursing staff who participated and later ceased working were replaced by new staff.

\subsection{Intervention}

The development of the intervention 'Grip on neuropsychiatric symptoms in institutionalized people with young-onset dementia' is described in full detail elsewhere (van Duinen-van den IJssel et al., 2018). The intervention aims to decrease the frequency, severity and prevalence of neuropsychiatric symptoms which may also result in changes in emotional exhaustion, depersonalisation, personal accomplishment, job satisfaction and job demands of the nursing staff. The focus is on early detection, proper analysis of the causes and corresponding treatment and evaluation of the treatment of neuropsychiatric symptoms.

The intervention consisted of an educational program and a web-based care program (Fig. 1). The educational program consisted of two sessions (2.5 and 1.5 hours) and a onetime brush-up session ( 1.5 hours) after six months, covering characteristics and care giving in young-onset dementia, the occurrence and persistence of neuropsychiatric symptoms and the relationship with unmet needs, the need for a multidisciplinary and methodical approach and the use of the care program. The educational program was delivered by the researchers Jeannette van Duinen and Britt Appelhof and offered to all staff working on the participating special care unit. After the second session the web-based care program was implemented, which consisted of five steps. The first step was a separate step in which the elderly care physician used a tool for the evaluation of the appropriateness of psychotropic drug prescription for neuropsychiatric symptoms (derived from a recently developed medication review (van der Spek et al., 2015)). The tool was applied for all residents within two months after the implementation of the intervention. After this initial evaluation the physicians could decide to perform a reevaluation at their own discretion. The other four steps were consecutive and formed a cycle. Detection of symptoms could take place during nursing staff usual daily observations or every six

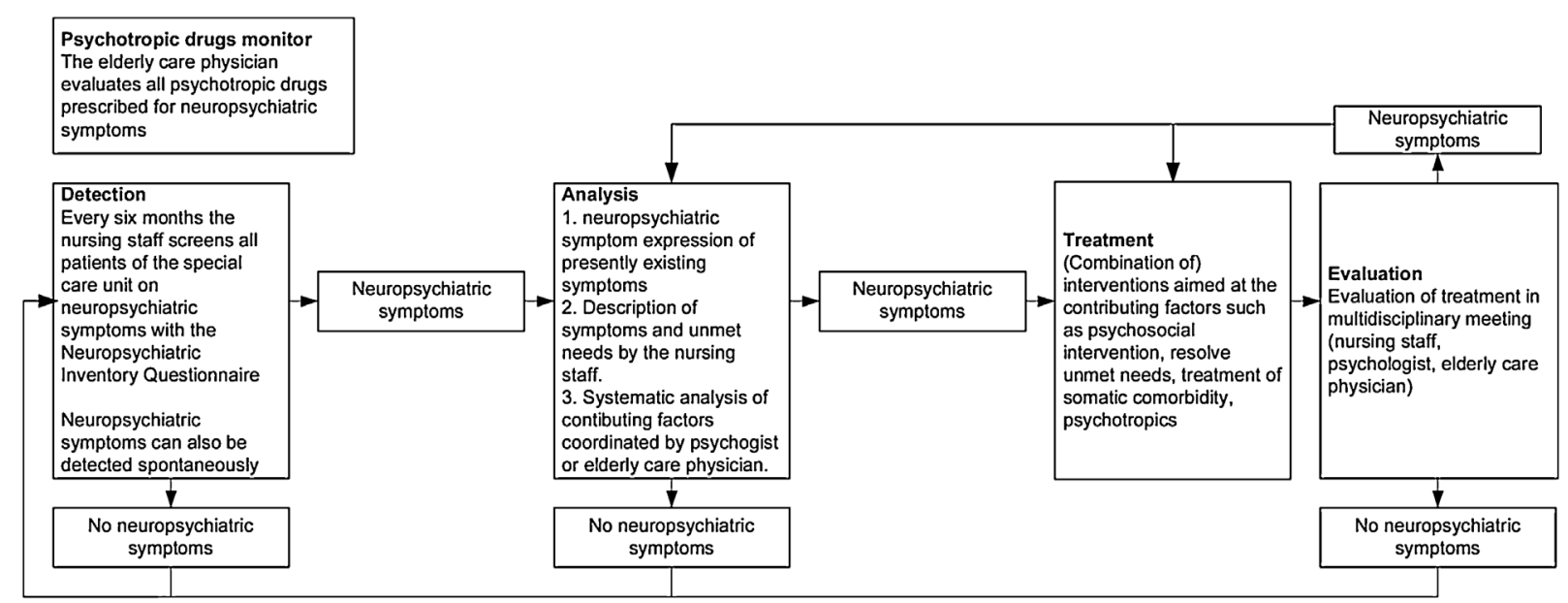

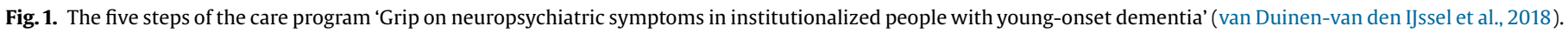
Note: Reprinted with permission. 
months with a screening tool by the vocational nurse. This tool was derived from the Neuropsychiatric Inventory Questionnaire (Kaufer et al., 2000). After detection of possible neuropsychiatric symptoms, nurses performed an analysis of possible causes. Specific attention was given to the presence of unmet needs as a cause of neuropsychiatric symptoms, because research has shown that unmet needs are highly prevalent in young-onset dementia and negatively associated with neuropsychiatric symptoms (Bakker et al., 2014). A needs assessment tool was derived from the Dutch version of the Camberwell Assessment of Need for the Elderly (van der Roest et al., 2008).When necessary, the analysis was continued by the elderly care physician or psychologist. The outcome of the analysis and the options for treatment were then discussed in multidisciplinary meetings, and a treatment plan was established. The treatment plan consisted of a description of the frequency and severity of the current behaviour and the aim in terms of frequency and severity of the behaviour. The intervention did not prescribe a specific treatment as this is based on the specific causes of the behaviour. In line with the guidelines, psychosocial treatments were preferred above treatment with psychotropic drugs. The treatment was evaluated by comparing the frequency and severity of the symptom before and after treatment. If the results of the evaluation were unsatisfactory the analysis could be redone or another treatment could be considered, else the detection phase would start again. All steps of the care program were supported by digital forms.

Alongside the implementation of the intervention a process evaluation was carried out to be able to interpret the results of this cluster randomised controlled trial. The results showed sufficient internal and external validity to evaluate the effect of the intervention on job characteristics of nursing staff (Appelhof et al., 2018).

\subsection{Care as usual}

Residents not receiving the intervention received care as usual. Care as usual was performed by the multidisciplinary team. Within the multidisciplinary team a care plan tailored to the individual needs and circumstances of the resident, is established and discussed half yearly. In frequent pre-arranged meetings the current condition of the resident as well as current quality of life are discussed. In case of neuropsychiatric symptoms, the nurse consults the healthcare psychologist or the elderly care physician or discusses the symptom in the pre-arranged meeting. The health care psychologist and/or elderly care physician analyses the symptom and, if necessary, establishes a treatment plan. The treatment is evaluated in the pre-arranged meeting.

\subsection{Data collection}

The research assistants contacted the site coordinator of the participating nursing homes one month before each assessment and asked for a list with the names and work-e-mail addresses of the care staff employed at the special care unit. At every assessment, the care staff received a web-based questionnaire via e-mail. Two weeks after the initial e-mail, two-weekly reminders were sent to the nonresponders for a period of 6 weeks. Because not everyone was familiar with web-based questionnaires, we also distributed paper and pencil questionnaires. To assure anonymity, the care staff returned these questionnaires directly to the researchers by means of a postage-paid return envelope.

\subsection{Ethical considerations}

The study protocol was approved by the Medical Ethics Committee region Arnhem/Nijmegen (file number: 2015-1558).
This research project was conducted according to the principles of the Declaration of Helsinki (version November 2013, www.wma. net) and is in agreement with the law regarding medical-scientific research in humans. Informed consent was asked after nursing homes had been randomly assigned to one of the three groups. The following procedure was used at every assessment: In the e-mail and in a letter attached to the questionnaire we explained that participation was voluntary, and participation could be withdrawn at any moment. We also stated that no information on participation or the content of the questionnaires was given to the nursing homes. Nursing staff agreed with participation by filling in the questionnaire.

\subsection{Primary outcomes}

Burnout was assessed with the Dutch version of the Maslach Burnout Inventory, known as the Utrecht Burnout Scale (UBOS). The UBOS-C version was used, which is suited for health care professionals (Maslach and Jackson, 1986; Schaufeli and Van Dierendonck, 2000). The original questionnaire contained 22items. However, in the Dutch version two items have been removed after confirmatory factor analysis in order to maintain a three factor structure (Schaufeli and Van Dierendonck, 2000). As a result, the questionnaire consists of 20 items with a seven-point scale ranging from 'never' (0) to 'always' (6). The questionnaire is well validated and assesses three components of burnout: emotional exhaustion (8 items range $0-48$ ), depersonalisation (5 items, range 0-30) and personal accomplishment (7 items, range 042) (Schaufeli and Van Dierendonck, 2000). A higher score on emotional exhaustion and depersonalisation and a lower score on personal accomplishment indicates a higher risk on burnout (Schaufeli and Van Dierendonck, 2000). Reference scores for all separate subscales are available, allowing for comparison of the scores (Schaufeli and Van Dierendonck, 2000).

Job satisfaction and job demands were assessed with two subscales of the Leiden Quality of Work Questionnaire (Van der Doef and Maes, 1999). This questionnaire is a validated and reliable instrument assessing thirteen job characteristics of nursing staff (Van der Doef and Maes, 1999). Job satisfaction consists of seven items (range 7-28) and job demands of six items (range 6-24). Questions are answered on a four-point Likert scale ranging from 'totally disagree' (1) to 'totally agree' (4). A higher score indicates that nurses perceive their job satisfaction and job demands as more positive.

\subsection{Other characteristics}

Date of birth, sex, and years of working experience, weekly working hours and educational level of the nursing staff were registered.

The process evaluation of this trial showed that there were differences in the degree to which the intervention was implemented on the special care units which may result in differences in effects (Appelhof et al., 2018). To control for the degree of implementation, this was conceptualized into an implementation score consisting of three components. The first component was the rate of use of the detection tool, based on the number of times the step was completed with regard to the number of residents on the special care units. If the tool was used at least once every six months for $75 \%-100 \%$ of the residents a score 2 was given, score 1 if used between 50 and $74 \%$, score 0 if used in $<50 \%$. The second component consisted of staff ratings of the percentages of cases with neuropsychiatric symptoms in which they worked according to the care program. A score was assigned to each special care units based on their answers (score 2 if used in between 75 and 100\% of the cases, 
score 1 if used between 50 and 74\%, score 0 if used in <50\%). The last aspect was the implementation rating of the researchers Jeannette van Duinen and Britt Appelhof who were closely involved in the implementation. They separately rated the implementation based on their communication with the special care units (at least once every six months by telephone or email) about the progress of the implementation (ranging from 0 to 2 ), with a higher score indicating better implementation). Disagreements were solved by discussion. The implementation scores were summed, resulting in a total implementation score ranging from 0 to 6 .

\subsection{Statistical analysis}

All analyses were performed using SPSS version 22. Demographic variables of the nursing staff at time of enrolment in the study were described by calculating means or proportions. All outcomes were checked for missing values, normality and outliers. Missing values were dealt with by linear mixed models on the basis of the missing at random assumption (Hedeker and Gibbons, 2006). Impact of this assumption was investigated by performing the analyses with optimistic and pessimistic imputation. On some of the questionnaires assessing job satisfaction and job demands,

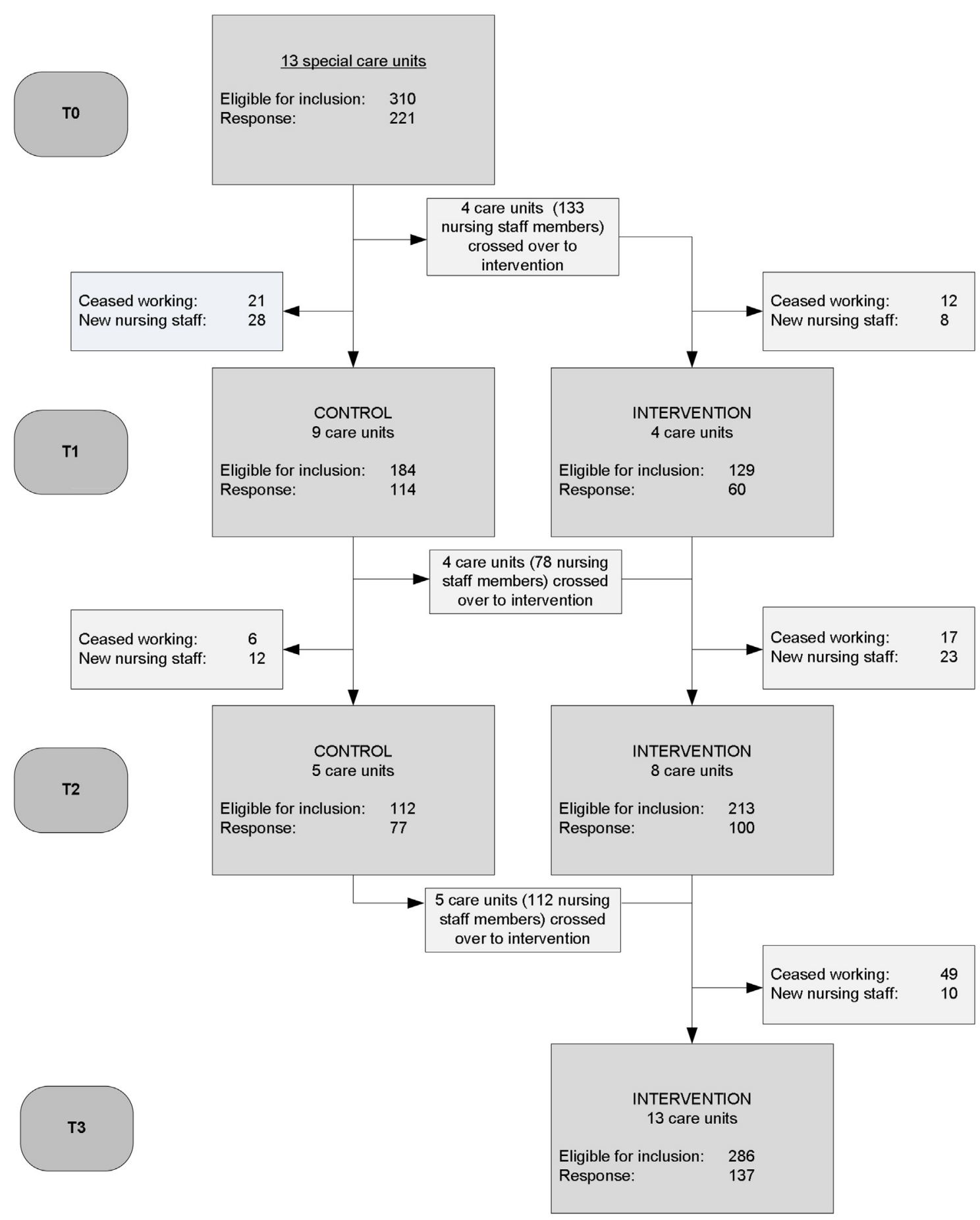

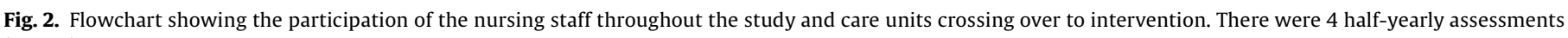
(T0-T3). 
respondents rated a question with both 'disagree' and 'agree'. In such cases it was assumed to be 'agree' for negatively formulated questions and 'disagree' for positively formulated questions. Impact of this assumption was investigated by performing the analyses with the other given answer.

Linear mixed models were used to take account for the clustering of the care staff within the special care units and for correlation of the repeated measures over time. With this model we estimated the main effect of the intervention and the main effect of time (on three categorical time points). The fit of the model was checked using residual plots and by comparing the observed and predicted profiles of special care units over time for each variable. Intraclass Correlation Coefficients were calculated from the variances at the three levels as follows:

Intraclass Correlation Coefficient repeatedmeasure

$$
=\frac{\text { variance }_{\text {care unit }}+\text { variance }_{\text {staff }}}{\text { variance }_{\text {care unit }}+\text { variance }_{\text {staff }}+\text { variance }_{\text {repeatedmeasure }}}
$$

and Intraclass Correlation Coefficient staff $_{\text {f }}$

$$
=\frac{\text { variance }_{\text {care unit }}}{\text { variance }_{\text {care unit }}+\text { variance }_{\text {staff }}}
$$

Additional interaction analyses were performed to investigate whether the effect of the intervention was different for higher educated staff (registered nurses compared to other ( $=$ all other educational levels)), the number of working hours per week of staff and implementation score (0-6). In all analyses, a p-value of $<0.05$ was considered statistically significant.

\section{Results}

In total, 305 (78\%) nursing staff members participated out of the 391 nursing staff members invited to participate during the course of the study. A total of 1234 questionnaires were distributed during the course of the study, of which 709 were returned (response rate $57.4 \%)$. At baseline, 221 nursing staff members participated in the study (Fig. 2). During the course of the study 84 new nursing staff members returned questionnaires. These nursing staff members were new employees on the special care unit or nursing staff members who did not return the questionnaires distributed in earlier assessments. Seventy-one nursing staff members returned questionnaires across all four assessments.

In Table 2, demographic characteristics are described over all participants in the study at time of their first assessment $(n=305)$. At time of inclusion in the study $(n=305)$, nursing staff mean age was 43.5 years and almost $92 \%$ was female. Almost $60 \%$ of all nursing staff members were a certified nursing assistant and almost $23 \%$ was a registered nurse. On average most staff members had 16 years of working experience, and were employed for $26 \mathrm{~h}$ per week (Table 2). At baseline, the number of residents on the care unit varied from 14 to 48 and the total number of nursing staff members working on the special care unit varied between 12 and 46 .
Table 2

Demographic characteristics of the nursing staff at time of inclusion in the study $(\mathrm{n}=305)$.

\begin{tabular}{lll}
\hline Age $^{\mathrm{a}}$ & $\begin{array}{l}\text { Mean (SD) } \\
\text { Range }\end{array}$ & $43.5(12.2)$ \\
Sex $^{\mathrm{b}}$ & $\mathrm{n}(\%$ female) & $17.8-64.6$ \\
Years of working experience $^{\mathrm{c}}$ & $\begin{array}{l}\text { Mean (SD) } \\
\text { Range }\end{array}$ & $16.2(10.8)$ \\
& $\mathrm{n}(\%)$ & $0-45$ \\
Educational level $^{\mathrm{d}}$ & & \\
$\quad$ Nursing assistant & & $33(11)$ \\
$\quad$ Certified nursing assistant & & $177(58.8)$ \\
$\quad$ Registered nurse $^{\text {Other }}$ & $68(22.6)$ \\
Working hours per week & $\mathrm{f}$ & $23(7.8)$ \\
& Mean (SD) & $26.2(6.7)$ \\
\hline a 40 missing. & Range & $0-36$ \\
b 1 missing. & & \\
c 5 missing. & \\
d 4 missing. & \\
e non-certified nursing assistants and recreational therapists. \\
f 35 missing.
\end{tabular}

Table 3

Baseline scores of the nursing staff on the outcome variables and range of the scales $(n=267)$.

\begin{tabular}{lll}
\hline Outcome & Mean (SD) & Range \\
\hline Burnout & & \\
$\quad$ Emotional exhaustion $^{\mathrm{a}}$ & $11.0(6.6)$ & $0-48$ \\
Depersonalisation $^{\mathrm{a}}$ & $2.7(2.9)$ & $0-30$ \\
$\quad$ Personal accomplishment $^{\mathrm{b}}$ & $32.3(5.7)$ & $0-42$ \\
Job satisfaction $^{\mathrm{c}}$ & $21.7(3.2)$ & $7-28$ \\
Job demands $^{\mathrm{d}}$ & $14.7(2.8)$ & $6-24$ \\
\hline
\end{tabular}

Note: Only the scores for staff included at T0 and staff included at T1 or T2 which not yet had been exposed to the intervention are shown.

a 1 missing.

b 6 missing.

10 missing.

d 8 missing.

Nursing staff who started participating in the study after the baseline assessment could already have been exposed to the intervention, depending on which group the care unit was assigned to (Fig. 2). As a result, the number of nursing staff $(n=267)$ with baseline data on the outcome of interest (Table 3) is lower than the number of nursing staff participating in the study. Missing values were found in a small percentage of the outcome variables $(0.1 \%$ $2.5 \%$ ) and in $4.9 \%$ on the variable 'weekly working hours'. According to the reference burnout risk scores, nursing staff had at baseline an average risk on emotional exhaustion and personal accomplishment and a low risk on depersonalisation; the mean score for job satisfaction was above average and the mean score of job demands was average (Table 3 ). Linear mixed models showed no significant effects of the intervention on the burnout subscales, job satisfaction and job demands (Table 4). Sensitivity analyses with respectively optimistic and pessimistic imputation did not yield different results.

Table 4

\begin{tabular}{|c|c|c|c|c|c|c|}
\hline & \multirow[t]{2}{*}{ Estimate } & \multirow[t]{2}{*}{$\mathrm{P}$} & \multicolumn{2}{|l|}{$95 \% \mathrm{CI}$} & \multirow[t]{2}{*}{ ICC repeated measure } & \multirow[t]{2}{*}{ ICC nurse } \\
\hline & & & Low & Up & & \\
\hline \multicolumn{7}{|l|}{ Burnout } \\
\hline Emotional exhaustion & -0.04 & .94 & -1.25 & 1.16 & 0.62 & 0.16 \\
\hline Depersonalisation & 0.24 & .35 & -0.26 & 0.74 & 0.59 & 0.07 \\
\hline Personal accomplishment & -0.82 & .123 & -1.86 & 0.22 & 0.59 & 0.07 \\
\hline Job satisfaction & -0.40 & .17 & -0.98 & 0.17 & 0.57 & 0.13 \\
\hline Job demands & -0.04 & .88 & -0.57 & 0.49 & 0.67 & 0.20 \\
\hline
\end{tabular}

Effects of the intervention on burnout, job satisfaction and job demands.

$\mathrm{CI}=$ confidence interval, $\mathrm{ICC}=$ intraclass correlation coefficient. 
In a separate interaction analysis, a statistically significant intervention effect was found for educational level on emotional exhaustion and job satisfaction. For registered nurses the intervention effect was 1.36 on emotional exhaustion, this means that in registered nurses the emotional exhaustion scores in the intervention condition were on average 1.36 points higher compared to the control condition. In non-registered nurses the emotional exhaustion scores in the intervention condition were on average 0.46 points lower compared to the control condition. Thus, the intervention effect for non-registered nurses was on average 1.8 points ( $95 \%$ confidence interval $(\mathrm{CI})$ : $0.14-3.50, \mathrm{p}=0.034$ ) lower than the intervention effect of registered nurses. Regarding job satisfaction, the intervention effect was -0.98 for registered nurses, meaning that job satisfaction scores were on average 0.98 points lower in the intervention condition compared to the control condition. For non-registered nurses job satisfaction scores were 0.18 points higher in the intervention condition compared to the control condition. Thus, the effect in registered nurses was 1.2 (95\% $\mathrm{CI}:-1.8$ to $-0.18, \mathrm{p}=0.017$ ) lower than the intervention effect for non-registered nurses.

We also found a significant interaction effect with regard to the implementation score, four special care units scored a 5 or 6 (maximum score) and three scored a 0 (minimum score) or 1 . We found a significant interaction effect between implementation score and intervention with regard to personal accomplishment: for every one-point increase in the score on implementation, the effect of the intervention increased with 0.33 points (95\% CI: 0.04 to $0.61, p=0.025$ ). Consequently, the intervention effect changed from -1.9 for special care units with an implementation score of 0 to $0.1\left(=-1.9+6^{*} 0.33\right)$ when the implementation score was 6 . No significant interaction effects between weekly working hours of staff and the intervention effect was found on any of the outcomes.

\section{Discussion}

To the best of our knowledge this is the first study evaluating a complex, multicomponent intervention for the management of neuropsychiatric symptoms in nursing home residents with young-onset dementia, and its effect on job satisfaction, job demands and burnout of nursing staff. We found that, in general, the intervention showed no effect compared to care as usual on the main outcome measures burnout, job satisfaction or on job demands. However, three different interaction effects were found. Compared to other staff members, registered nurses' emotional exhaustion scores slightly increased while job satisfaction slightly decreased when using the intervention. Furthermore, the staffs' feelings of personal accomplishment decreased in special care units with the lowest implementation score (0), while this decrease diminished with every one-point increase in implementation-score. Consequently, in staff working in special care units with an implementation score of 6 , no change in personal accomplishment was observed.

Our findings show that the nursing staff already scored well on the outcomes of interest before implementation of the intervention. For instance, scores on emotional exhaustion, depersonalisation and personal accomplishment indicated that the nursing staff was not at high risk for developing burnout at time of inclusion. In comparison with other Dutch studies on nursing staff caring for nursing home residents with late-onset dementia, scores on the burnout subscales, job satisfaction and job demands were similar (de Rooij et al., 2012; Willemse et al., 2014; Zwijsen et al., 2015). Interestingly, in another paper that was part of the Beyond-II study we found that a larger majority of the nursing staff members caring for people with young-onset dementia reported medium or high distress related to neuropsychiatric symptoms (van Duinen-van den IJssel et al., 2017). The distress could consist of occupational disruptiveness, such as a change in work routine but also emotional distress. Contrary to our expectations this was not reflected in the burnout scores, job satisfaction and job demands scores. Neuropsychiatric symptoms in young-onset dementia are highly prevalent and frontotemporal dementia, which is associated with unique behavioural changes, is more common in younger compared to older people with dementia (Mulders et al., 2016). It could be that nursing staff working on care units for people with young-onset dementia were likely already aware of these specific issues in younger people when they applied to a nursing job on these special care units. In other words, they have consciously chosen to work on these special care units despite the challenges of neuropsychiatric symptoms. Furthermore, neuropsychiatric symptoms and distress are closely related to each other. Burnout, job satisfaction and job demands are influenced by neuropsychiatric symptoms but also by other factors among which social support, job control and caring climate (Brodaty et al., 2003; Chamberlain et al., 2016; Edvardsson et al., 2009; Lapane and Hughes, 2007; Schmidt et al., 2014; Willemse et al., 2012). Unfortunately, we were unable to investigate the effects of the intervention on the distress scores, because the distress scores were assessed with the neuropsychiatric inventory nursing home version (Wood et al., 2000) and linked to the scores of the residents.

Our results seems to contradict the earlier findings of Zwijsen et al. (2015), who found that the intervention resulted in higher levels of job satisfaction in nursing staff. However, results of this study cannot be compared directly with our findings because of differences between the two studies (van Duinen-van den IJssel et al., 2018; Zwijsen et al., 2011). For instance, we only included special care units of nursing homes affiliated with the Dutch young-onset dementia knowledge centre; as such these nursing homes may already have more specialized knowledge regarding the treatment of neuropsychiatric symptoms compared to other nursing homes. Therefore, the contrast between the nursing homes may have been too low. This appears to be confirmed by the results of the process evaluation that was performed alongside implementation of our intervention, showing overlap between working methods of the intervention and working methods of care as usual within these particular health care organizations (Appelhof et al., 2018). For example, in some special care units nursing staff already worked with a neuropsychiatric symptom detection tool or analysis form (Appelhof et al., 2018).

We might have underestimated the effects of these specific aspects on the outcomes of interest and therefore, some aspects regarding the design of our study might have to be reconsidered. We did not use all steps from a specific framework to guide the adaptation of the original care program for the use in young-onset dementia in our study. A framework, such as the Medical Research Council framework, helps to gain insight in the active ingredients of the intervention and how these exert their effect (Craig et al., 2013). Although, we used an implementation strategy and investigated barriers and facilitators for optimizing the implementation of our intervention this may have given us too little insight in all active ingredients (Appelhof et al., 2018; van Duinenvan den IJssel et al., 2018). For instance, regarding co-worker and supervisor support and team attitude towards change. Furthermore, we did not perform a pilot study which is recommended by the Medical Research Council as well as the Reach Effectiveness Adoption Implementation Maintenance framework (Boersma et al., 2015; Craig et al., 2013). This probably would have given us more insight in the overlap between working methods and satisfaction with the current working method.

Our interaction analysis showed that the intervention effect differed between registered nurses compared to non-registered nurses, which means they can be interpreted separately. In our study, $23 \%$ of the nursing staff members were a registered nurse, 
which seems to be higher compared to other Dutch studies on nursing staff working on care units for people with late-onset dementia, with percentages of $10.3 \%$ and $14 \%$ respectively (Willemse et al., 2014; Zwijsen et al., 2015). The effect of our intervention on emotional exhaustion as well as job satisfaction as perceived by registered nurses was small and does not seem to be clinically relevant. However, Zwijsen et al. (2015) also found that emotional exhaustion scores increased in higher educated staff (Zwijsen et al., 2015). It may be that registered nurses are more aware of the needs of a resident (Kada et al., 2009; Lintern, 2001). In our care program we placed emphasis on the detection of unmet needs of the resident. This may have increased awareness that a need still could be unmet despite efforts of the staff which could result in feeling emotionally overextended. This could be further complicated by the limited possibilities within the nursing home to fulfil these needs (Edberg et al., 2008; Edvardsson et al., 2009). Another explanation is related to a recent change in Dutch nursing homes in which teams, and especially registered nurses, have to perform managerial tasks themselves besides their regular tasks. Furthermore, they are mostly involved in the implementation of interventions. Our process evaluation showed that the implementation of the care program was moderate in some special care units (Appelhof et al., 2018). Besides that, some of the tools in our care program were rated as too time consuming and nursing staff mentioned that it was not feasible to use the care program in the time available to them (Appelhof et al., 2018). These issues may have influenced job satisfaction. As this is found to be a predictor of emotional exhaustion of staff (Kalliath and Morris, 2002), decreased job satisfaction may result in increased emotional exhaustion.

Furthermore, we found an interaction effect between the intervention and implementation regarding personal accomplishment, which was small. Perhaps, not succeeding in the implementation may feel as a personal failure, which may decrease personal accomplishment. However, this finding may also be the result of multiple testing.

A strength of this study is that, we were the first to include such a large group of nursing staff working with young-onset dementia nursing home residents. However, there are some limitations in this study that need to be taken into consideration. The primary outcome of the BEYOND-II study was agitation and aggression and the study was powered on this outcome and not on the job related outcomes (van Duinen-van den IJssel et al., 2018). It is possible that we included too few nursing staff members to detect changes in these outcomes. Furthermore, in some special care units there was a relatively low participation rate, resulting in a few small clusters. This may not reflect the overall burnout scores, job satisfaction and job demands in these special care units and may be too small to detect subtle differences in changes in job satisfaction, job demands and burnout-complaints. We were unable to blind the nursing staff for the intervention condition, which is inherent to this kind of research. This may have influenced the results.

In conclusion, no differences could be found between the intervention and care as usual on burnout, job satisfaction and job demands. Our findings demonstrate that staff working on care units for people with young-onset dementia already scored well on these outcomes. Furthermore, in comparison with care units for older people there is a high number of registered nurses on special care units for people with young-onset dementia. In our study, as well as other studies, there was a small increase in emotional exhaustion scores of registered nurses compared to non-registered nurses. This recurring finding warrants further studies into emotional exhaustion of registered nurses. Our findings contribute to the scarce knowledge about staff caring for institutionalized people with young-onset dementia. In light of the current findings future studies should investigate the effectiveness of the intervention in nursing homes that lack a structured method while taking the recommendations into account.

\section{Conflict of interest}

None.

\section{Description of authors' roles}

This study was designed by Christian Bakker, Raymond T.C.M. Koopmans, Martin Smalbrugge, Sytse U. Zuidema, Sandra A. Zwijsen and Steven Teerenstra. The implementation of the intervention was carried out by Jeannette C.L. van Duinen-van den IJssel and Britt Appelhof. Christian Bakker coordinated the study. The data was collected by Jeannette C.L. van Duinen-van den IJssel, Britt Appelhof, Mandy Wijnen and Yvette Daniels. Jeannette C.L. van Duinen-van den IJssel wrote the article and Christian Bakker assisted in writing the article. Steven Teerenstra assisted in performing the analyses. Sandra A. Zwijsen, Martin Smalbrugge, Frans R. J. Verhey, Britt Appelhof, Marjolein E. de Vugt, Sytse U. Zuidema, Steven Teerenstra, Christian Bakker and Raymond T.C.M. Koopmans assisted in the interpretation of the data and critically reviewed the article.

\section{Acknowledgements}

This study was funded by the Netherlands Organization for Health Research and Development (ZonMw nr:733050402), Archipel Care Group in the Netherlands, Florence Care Group in the Netherlands, the Dutch Alzheimer Society and the Dutch Young-onset dementia Knowledge Centre. We are grateful for the cooperation of the staff of the participating nursing homes. We thank Mandy Wijnen and Yvette Daniels for collecting the data.

\section{References}

Appelhof, B., Bakker, C., van Duinen-van den IJssel, J.C.L., Zwijsen, S.A., Smalbrugge, M. Verhey, F.R.J., de Vugt, M.E., Zuidema, S.U., Koopmans, R., 2018. Process evaluation of an intervention for the management of neuropsychiatric symptoms in young-onset dementia. J. Am. Med. Dir. Assoc. 19 (8), 663-671.

Appelhof, B., Bakker, C., de Vugt, M.E. van Duinen-van den IJssel, J.C.L.,Zwijsen, S.A. Smalbrugge, M., Teerenstra, S., Verhey, F.R.J., Zuidema, S.U., Koopmans, R.T.C.M. 2019. Effects of a multidisciplinary intervention on the presence of neuropsychiatric symptoms and psychotropic drug use in nursing home residents with young-onset dementia: behavior and evolution of young onset dementia part 2 (BEYOND-II) study. Am. J. Geriatr. Psychiatry (In press).

Bakker, C., de Vugt, M.E., van Vliet, D., Verhey, F.R., Pijnenburg, Y.A., Vernooij-Dassen, M.J.F.J., Koopmans, R.T.C.M., 2014. The relationship between unmet care needs in young-onset dementia and the course of neuropsychiatric symptoms: a two year follow-up study. Int. Psychogeriatr. 26 (12), 1991-2000.

Boersma, P., van Weert, J.C., Lakerveld, J., Droes, R.M., 2015. The art of successful implementation of psychosocial interventions in residential dementia care: systematic review of the literature based on the RE-AIM framework. Int Psychogeriatr. 27 (1), 19-35.

Brodaty, H., Draper, B., Low, L.F. 2003. Nursing home staff attitudes towards residents with dementia: strain and satisfaction with work. J. Adv. Nurs. 44 (6), 583-590.

Brown, C.A., Lilford, R.J., 2006. The stepped wedge trial design: a systematic review. BMC Med. Res. Methodol. 6, 54.

Carter, J.E., Oyebode, J.R., Koopmans, R., 2018. Young-onset dementia and the need for specialist care: a national and international perspective. Aging Ment. Health 22 (4), 468-473.

Chamberlain, S.A., Hoben, M., Squires, J.E., Estabrooks, C.A., 2016. Individual and organizational predictors of health care aide job satisfaction in long term care. BMC Health Serv. Res. 16 (1), 577.

Craig P. Dieppe, P., Macintyre, S., Michie, S., Nazareth, I., Petticrew, M., 2013. Developing and evaluating complex interventions: the new Medical Research Council guidance. Int. J. Nurs. Stud. 50 (5), 587-592.

de Jonge, J., Le Blanc, P.M., Peeters, M.C., Noordam, H., 2008. Emotional job demands and the role of matching job resources: a cross-sectional survey study among health care workers. Int. J. Nurs. Stud. 45 (10), 1460-1469.

de Rooij, A.H., Luijkx, K.G., Declercq, A.G., Emmerink, P.M., Schols, J.M., 2012 Professional caregivers' mental health problems and burnout in small-scale and traditional long term care settings for elderly people with dementia in the Netherlands and Belgium. J. Am. Med. Dir. Assoc. 13 (5), e487-411 486. 
Edberg, A.K., Bird, M., Richards, D.A., Woods, R., Keeley, P., Davis-Quarrell, V., 2008. Strain in nursing care of people with dementia: nurses' experience in Australia, Sweden and United Kingdom. Aging Ment. Health 12 (2), 236-243.

Edvardsson, D., Sandman, P.O., Nay, R., Karlsson, S., 2009. Predictors of job strain in residential dementia care nursing staff. J. Nurs. Manag. 17 (1), 59-65.

Evers, W., Tomic, W., Brouwers, A., 2001. Effects of aggressive behavior and perceived self-efficacy on burnout among staff of homes for the elderly. Issues Ment. Health Nurs. 22 (4), 439-454.

Harrington, C., Swan, J.H., 2003. Nursing home staffing, turnover, and case mix. Med Care Res. Rev. 60 (3), 366-392 discussion 393-369.

Hazelhof, T.J., Schoonhoven, L., van Gaal, B.G., Koopmans, R.T., Gerritsen, D.L., 2016 Nursing staff stress from challenging behaviour of residents with dementia: a concept analysis. Int. Nurs. Rev. 63 (3), 507-516.

Hedeker, D., Gibbons, R.D., 2006. Missing data in longitudinal studies. Longitudinal Data Analysis,

Kada, S., Nygaard, H.A., Mukesh, B.N., Geitung, J.T., 2009. Staff attitudes towards institutionalised dementia residents. J. Clin. Nurs. 18 (16), 2383-2392.

Kalliath, T., Morris, R., 2002. Job satisfaction among nurses: a predictor of burnout levels. J. Nurs. Adm. 32 (12), 648-654.

Kaufer, D.I., Cummings, J.L., Ketchel, P., Smith, V., MacMillan, A., Shelley, T., Lopez, O. L., DeKosky, S.T., 2000. Validation of the NPI-Q a brief clinical form of the neuropsychiatric inventory. J. Neuropsychiatry Clin. Neurosci. 12 (2), 233-239.

Lapane, K.L., Hughes, C.M., 2007. Considering the employee point of view: perceptions of job satisfaction and stress among nursing staff in nursing homes. J. Am. Med. Dir. Assoc. 8 (1), 8-13.

Lintern, T., 2001. Quality in Dementia Care: Evaluating Staff Attitudes and Behaviour. University of Wales, Bangor.

Maslach, C., Jackson, S.E., 1981. The measurement of experienced burnout. J. Occup. Behav. 2, 99-113.

Maslach, C., Jackson, S.E., 1986. The Maslach Burnout Inventory Manual. Consulting Psychology Press, Inc, Palo Alto, CA.

Ministry of Health Welfare and Sport, 2017. Aan het werk voor ouderen!.

Mulders, A.J.M.J., Fick, I.W., Bor, H., Verhey, F.R., Zuidema, S.U., Koopmans, R.T., 2016 Prevalence and correlates of neuropsychiatric symptoms in nursing home patients with young-onset dementia: the beyond study.J. Am. Med. Dir. Assoc.17 (6), 495-500.

Rodney, V., 2000. Nurse stress associated with aggression in people with dementia: its relationship to hardiness, cognitive appraisal and coping. J. Adv. Nurs. 31 (1), $172-180$.

Schaufeli, W., Van Dierendonck, D., 2000. UBOS, Utrecht Burnout Scale: Manual. SWETS Test Publishers, Zeist.

Schmidt, S.G., Dichter, M.N., Palm, R., Hasselhorn, H.M., 2012. Distress experienced by nurses in response to the challenging behaviour of residents - evidence from German nursing homes. J. Clin. Nurs. 21 (21-22), 3134-3142.

Schmidt, S.G., Dichter, M.N., Bartholomeyczik, S., Hasselhorn, H.M., 2014. The satisfaction with the quality of dementia care and the health, burnout and work ability of nurses: a longitudinal analysis of 50 German nursing homes. Geriatr. Nurs. 35 (1), 42-46.

Van der Doef, M., Maes, S., 1999. The Leiden quality of work questionnaire: its construction, factor structure, and psychometric qualities. Psychol. Rep. 85, 963-970.

van der Roest, H.G., Meiland, F.J., van Hout, H.P., Jonker, C., Droes, R.M., 2008. Validity and reliability of the Dutch version of the Camberwell Assessment of Need for the Elderly in community-dwelling people with dementia. Int. Psychogeriatr. 20 (6), 1273-1290.

van der Spek, K., Gerritsen, D.L., Smalbrugge, M., Nelissen-Vrancken, M.H., Wetzels, R.B. Smeets, C.H. Zuidema, S.U., Koopmans, R.T. 2015. A reliable and valid index was developed to measure appropriate psychotropic drug use in dementia. J. Clin. Epidemiol. 68 (8), 903-912.

van Duinen-van den IJssel, J.C.L., Mulders, A., Smalbrugge, M., Zwijsen, S.A., Appelhof, B., Zuidema, S.U., de Vugt, M.E., Verhey, F.R.J., Bakker, C., Koopmans, R. 2017. Nursing staff distress associated with neuropsychiatric symptoms in young-onset dementia and late-onset dementia. J. Am. Med. Dir. Assoc. 19 (7), 627-632.

van Duinen-van den IJssel, J.C.L., Appelhof, B., Zwijsen, S.A., Smalbrugge, M., Verhey, F.R.J., de Vugt, M.E., Zuidema, S.U., Koopmans, R., Bakker, C., 2018. Behavior and Evolution of Young ONset Dementia part 2 (BEYOND-II) study: an intervention study aimed at improvement in the management of neuropsychiatric symptoms in institutionalized people with young onset dementia. Int. Psychogeriatr. 30 (3), 437-446.

Vernooij-Dasssen, M.J., Faber, MJ. Olde Rikkert, M.G. Koopmans, R.T, van Achterberg, T., Braat, D.D., Raas, G.P., Wollersheim, H., 2009. Dementia care and labour market: the role of job satisfaction. Aging Ment. Health 13 (3), 383390.

Willemse, B.M., de Jonge, J., Smit, D., Depla, M.F., Pot, A.M., 2012. The moderating role of decision authority and coworker- and supervisor support on the impact of job demands in nursing homes: a cross-sectional study. Int. J. Nurs. Stud. 49 (7), 822-833.

Willemse, B.M., Depla, M.F., Smit, D., Pot, A.M., 2014. The relationship between small-scale nursing home care for people with dementia and staff's perceived job characteristics. Int. Psychogeriatr. 26 (5), 805-816.

Wood, S., Cummings, J.L., Hsu, M.A., Barclay, T., Wheatley, M.V., Yarema, K.T., Schnelle, J.F., 2000. The use of the neuropsychiatric inventory in nursing home residents. Characterization and measurement. Am. J. Geriatr. Psychiatry 8 (1), $75-83$.

Zwijsen, S.A., Smalbrugge, M., Zuidema, S.U., Koopmans, R.T.C.M., Bosmans, J.E., van Tulder, M.W., Eefsting, J.A., Gerritsen, D.L., Pot, A.M., 2011. Grip on challenging behaviour: a multidisciplinary care programme for managing behavioural problems in nursing home residents with dementia. Study protocol. BMC Health Serv. Res. 11 (41), 1-6.

Zwijsen, S.A., Kabboord, A., Eefsting, J.A., Hertogh, C.M., Pot, A.M., Gerritsen, D.L., Smalbrugge, M., 2014a. Nurses in distress? An explorative study into the relation between distress and individual neuropsychiatric symptoms of people with dementia in nursing homes. Int. J. Geriatr. Psychiatry 29 (4), 384-391.

Zwijsen, S.A., Smalbrugge, M., Eefsting, J.A., Twisk, J.W., Gerritsen, D.L., Pot, A.M., Hertogh, C.M., 2014b. Coming to grips with challenging behavior: a cluster randomized controlled trial on the effects of a multidisciplinary care program for challenging behavior in dementia. J. Am. Med. Dir. Assoc. 15 (7), 531 e531531.e510.

Zwijsen, S.A., Gerritsen, D.L., Eefsting, J.A., Smalbrugge, M., Hertogh, C.M., Pot, A.M., 2015. Coming to grips with challenging behaviour: a cluster randomised controlled trial on the effects of a new care programme for challenging behaviour on burnout, job satisfaction and job demands of care staff on dementia special care units. Int. J. Nurs. Stud. 52 (1), 68-74. 